RESIDENT

\& FELLOW

SECTION

Section Editor

Mitchell S.V. Elkind,

MD, MS

Nabila Dahodwala, MD, MS

Ana-Claire Meyer, MD, MSHS

Address correspondence and reprint requests to Dr. Nabila Dahodwala, University of Pennsylvania, 330 S. 9th St, 2nd floor, Philadelphia, PA 19107 dahodwan@mail.med.upenn.edu

\title{
Emerging Subspecialties in Neurology: Health services research
}

This time, there is no debate about whether all Americans should have quality, affordable health care: the only question is, how?

—President Barack Obama, Washington, DC, 2009

At one end of the research spectrum, biomedical research asks, "What causes disease and how can it be prevented or treated under ideal circumstances?" The findings from biomedical research lead a health services researcher at the other end of the spectrum to ask, "What works and what does it cost in real-world settings?" Within neurology, advances in basic science and clinical and translational research have led to newer, more effective therapies and state-of-the-art diagnostic tools for neurologic conditions. As a result, neurologists now face an emerging set of questions about how to implement the following advances:

- How can we structure our health care systems to deliver the highest quality neurologic care in a cost-efficient manner?

- How do we improve equitable access to the advances in neurologic care and thereby reduce health disparities?

- Which innovations will improve health outcomes for neurologic disorders?

Health services research (HSR) seeks out evidencebased answers to these and related questions about clinical and cost effectiveness, health outcomes, quality of care, and health care delivery. ${ }^{2}$ For example, HSR analyzes the best evidence through systematic reviews, practice guidelines, and clinical prediction rules. In addition, HSR evaluates the effectiveness and quality of health care at the patient, community/population, and health systems levels. With health care reform imminent, evidence from HSR, such as comparative effectiveness analysis, is vital to inform health policy makers and community leaders who make decisions about the organization and financing of health care. Although several leaders in neurology recognize the need to train more health services researchers, currently there are few neurologists trained in HSR. ${ }^{3}$ Ultimately, our inaction in this field will allow others to shape the debates that critically affect neurologists' clinical practice, reimbursement, and importantly, the health of our patients.

In the following sections, we discuss the history of HSR, training opportunities, and career options for neurologists.

HISTORY HSR can trace its roots to the mid 1800s when physicians, hospitals, and states began collecting information on mortality, morbidity, and disability. Over the next 100 years, HSR has evolved in its definition, expanded its role in health care, and formalized into an independent arm of research.

The development of national organizations, health journals, and government agencies related to health services has further solidified its importance. In 1936, the Robert Wood Johnson Foundation was created to improve the health and health care of all Americans, and has continued to be a major supporter of HSR. In the 1960s, journals such as Medical Care and Health Services Research were founded and began to publish HSRfocused scientific articles. Then, in the 1970s, the Veteran's Administration (VA) established a Health Services Research and Development (HSR\&D) program office for research and Congress established the National Center for Health Services Research, now the Agency for Healthcare Research and Quality (AHRQ). In addition to the VA's HSR\&D and AHRQ, several institutes through the NIH including the National Institute on Aging, National Institute of Mental Health, National Cancer Institute, and National Heart, Lung and Blood Institute are government sponsors for HSR. In 1994, the Institute of Medicine published a report on the importance of training and funding for HSR. ${ }^{4}$ Finally, 2 premier organizations representing health policy and health services research were founded in the late 1970 s and early 1980s. In this century, they have merged to form AcademyHealth, the leading professional society and resource for health services researchers. 


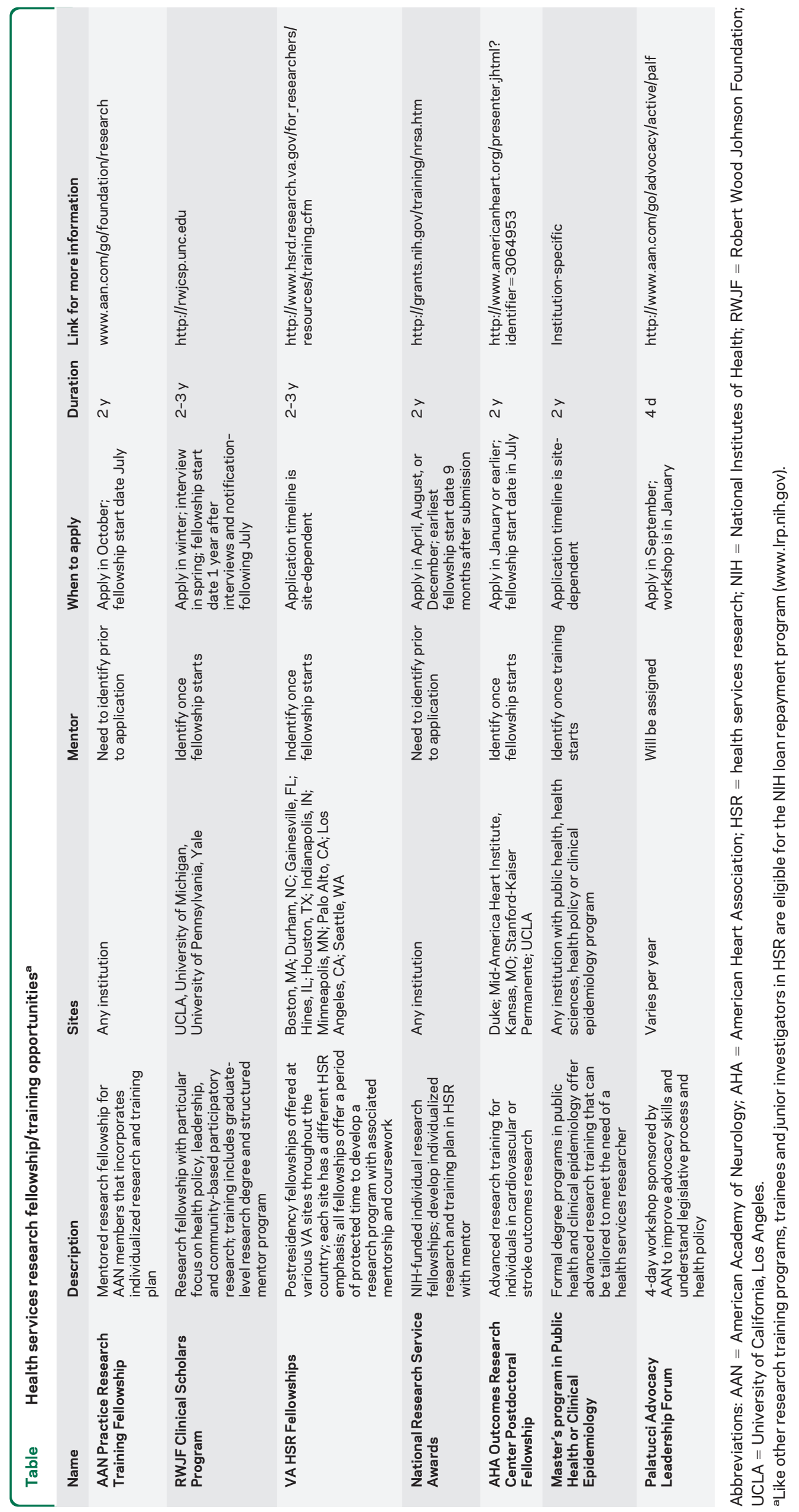


While HSR in neurology has been limited, the field is growing. For instance, since the introduction of American Academy of Neurology practice parameters 20 years ago, there have been over 90 published clinical guidelines from nearly every subspecialty of neurology. Similarly, a Medline search using the keywords "health services" or "health policy" and "neurology" performed by the authors revealed that the number of published articles related to health services in neurology has increased sevenfold over the last 20 years.

Opportunities for training and fellowships in HSR have grown as well (table). Given the multidisciplinary nature of HSR, it is essential that programs provide training and faculty mentors from a wide range of disciplines such as epidemiology, statistics, economics, anthropology, health policy, and psychology.

WHY CHOOSE A CAREER IN HEALTH SERVICES RESEARCH IN NEUROLOGY? HSR is a versatile field with tangible impact at the community level. HSR methods can be applied to any subspecialty within neurology. Some examples include a comparison of the costs of surgery vs medical management of epilepsy ${ }^{5}$ and the development of quality of care indicators in Parkinson disease. ${ }^{6}$ Evidence from HSR has led to changes in practice such as the development of primary stroke centers to improve quality of care. ${ }^{7}$

In addition, HSR questions often entail collaboration across disciplines such as emergency medicine, intensive care, primary care, geriatrics, and global health. For example, one innovative program integrates services from primary care, geriatrics, community-based agencies, and neurologists to develop a dementia disease management intervention. ${ }^{8}$ Other global health initiatives in countries such as China and Zambia develop and evaluate community-based approaches to epilepsy care in regions with few neurologists. ${ }^{9,10}$

Moreover, health services researchers can pursue careers in many settings, including academia, professional organizations, health policy groups, clinical settings, hospital administration, for-profit companies, and international, federal, state, and local agencies. Currently, neurologists trained in HSR are employed as professors in top neurology programs, conduct clinical trials for pharmaceutical companies or for nongovernmental or- ganizations such as the Gates Foundation, and serve as policy makers through government agencies.

Finally, opportunities to get involved in HSR are growing rapidly. Health services researchers in neurology have a vital role to play in addressing emerging national issues such as health care reform, patient safety, quality initiatives such as pay for performance, and the changing role of health information technology. Ultimately, it is both challenging and rewarding to spend a career improving the health of not only individuals, but also communities.

\section{DISCLOSURE}

Dr. Dahodwala has received support from the Robert Wood Johnson Foundation. Dr. Meyer is funded by the American Academy of Neurology Practice Research Training Fellowship and has received support from the Robert Wood Johnson Foundation.

\section{REFERENCES}

1. Holloway RG, Ringel SP. Narrowing the evidencepractice gap: strengthening the link between research and clinical practice. Neurology 1998;50:319-321.

2. Wells KB. Treatment research at the crossroads: the scientific interface of clinical trials and effectiveness research. Am J Psychiatry 1999;156:5-10.

3. Ringel SP, Steiner JF, Vickrey BG, Spencer SS. Training clinical researchers in neurology. Neurology 2001;57:388-392.

4. Field MJ, Tranquada RE, Feasley JC, eds. Health Services Research: Work Force and Educational Issues. Washington, DC: National Academy Press; 1995.

5. Langfitt JT, Holloway RG, McDermott MP, et al. Health care costs decline after successful epilepsy surgery. Neurology 2007;68:1290-1298.

6. Cheng EM, Siderowf A, Swarztrauber K, Eisa M, Lee M, Vickrey BG. Development of quality of care indicators for Parkinson's disease. Mov Disord 2004;19:136-150.

7. Alberts MJ, Hademenos G, Latchaw RE, et al. Recommendations for the establishment of primary stroke centers. Brain Attack Coalition JAMA 2000;283:3102-3109.

8. Vickrey BG, Mittman B, Connor K, et al. The effect of a disease management intervention on quality and outcomes of dementia care: a randomized controlled trial. Ann Intern Med 2006;145:713-726.

9. Wang W, Wu J, Dai X, et al. Global campaign against epilepsy: assessment of a demonstration project in rural China. Bull World Health Organ 2008;86:964-969.

10. Birbeck G, Chomba E, Atadzhanov M, Mbewe E, Haworth A. The social and economic impact of epilepsy in Zambia: a cross-sectional study. Lancet Neurol 2007;6: $39-44$. 


\section{Neurology}

\section{Emerging Subspecialties in Neurology: Health services research \\ Nabila Dahodwala and Ana-Claire Meyer \\ Neurology 2010;74;e37-e39 \\ DOI 10.1212/WNL.0b013e3181d31e6f}

\section{This information is current as of March 8, 2010}

\section{Updated Information \& Services}

\section{References}

Subspecialty Collections

Permissions \& Licensing

Reprints including high resolution figures, can be found at: http://n.neurology.org/content/74/10/e37.full

This article cites 9 articles, 3 of which you can access for free at: http://n.neurology.org/content/74/10/e37.full\#ref-list-1

This article, along with others on similar topics, appears in the following collection(s):

All Education

http://n.neurology.org/cgi/collection/all_education All Health Services Research

http://n.neurology.org/cgi/collection/all_health_services_research

Information about reproducing this article in parts (figures,tables) or in its entirety can be found online at:

http://www.neurology.org/about/about_the_journal\#permissions

Information about ordering reprints can be found online:

http://n.neurology.org/subscribers/advertise

Neurology ${ }^{\circledR}$ is the official journal of the American Academy of Neurology. Published continuously since 1951, it is now a weekly with 48 issues per year. Copyright. All rights reserved. Print ISSN: 0028-3878. Online ISSN: 1526-632X.

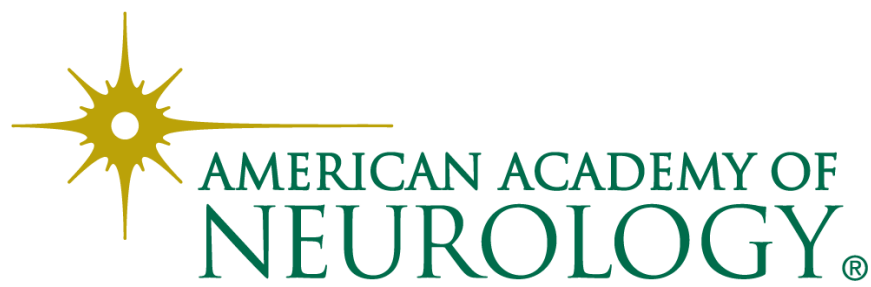

